This item was submitted to Loughborough's Research Repository by the author.

Items in Figshare are protected by copyright, with all rights reserved, unless otherwise indicated.

\title{
Environmental technology and the future of flight
}

PLEASE CITE THE PUBLISHED VERSION

http://dx.doi.org/10.1108/S2044-9941(2013)0000004004

PUBLISHER

(c) Emerald Group Publishing

VERSION

SMUR (Submitted Manuscript Under Review)

LICENCE

CC BY-NC-ND 4.0

REPOSITORY RECORD

Budd, Lucy C.S., and Thomas Budd. 2019. "Environmental Technology and the Future of Flight". figshare. https://hdl.handle.net/2134/17610. 


\title{
Environmental technology and the future of flight
}

Lucy Budd and Thomas Budd

\begin{abstract}
Purpose - To examine the role of new aeronautical technologies in improving commercial aviation's environmental performance.

Methodology/approach - Reviews the environmental improvements that may be conferred through the adoption of alternative aviation fuels and new airframe, engine and navigation technologies.

Findings - Although aeronautical technologies have evolved considerably since the earliest days of powered flight, the aviation industry is now reaching a point of diminishing returns as growing global consumer demand for air transport outstrips incremental improvements in environmental efficiency. The chapter describes some of the technological interventions that are being pursued to improve aviation's environmental performance and discusses the extent to which these innovations will help to deliver a more sustainable aviation industry.
\end{abstract}

\section{Introduction}

Commercial aviation is one of the most important components of the global economy yet also one of the most contentious. In a little over 100 years between the Wright brothers' first flights in December 1903 and today, the rapid development and subsequent ready-availability of safe, reliable, and relatively cheap access to air travel worldwide has transformed the mobility patterns, employment prospects, and consumption practices of millions of people on earth and global society's appetite for, and socio-economic reliance on, flying shows no signs of abating. According to the Air Transport Action Group, 2.8 billion passengers and almost 48 million tonnes of airfreight (worth some US\$5.3 trillion) were flown around the world on 26.7 million commercial flights in 2011 (ATAG, 2012). It is estimated that 56.6 million people worldwide are employed by the sector and commercial aviation's economic impact is thought to be in the region of US\$2.2 trillion (equivalent to approximately $3.5 \%$ of the World's GDP). Indeed, commercial aviation's economic impact is such that if the sector was a country, it would be ranked $19^{\text {th }}$ in the World by GDP (ibid, 2012).

For those who can afford the price of an air ticket, the world's commercial airline network allows personal and professional relationships to be conducted at a distance and across multiple time zones. It enables tourists and vacationers to experience foreign countries, climates, and cultures, and permits business travellers, students, and migrants to rapidly access new commercial, educational, and entrepreneurial opportunities overseas. It allows politicians, diplomats, business leaders, academics, and doctors to exchange knowledge and rapidly respond to natural disasters and humanitarian emergencies anywhere in the world. The co-evolution of intricate and integrated justin-time networks of air and surface logistics also enable high-value consumer goods, perishable foodstuffs and pharmaceuticals to be routinely and rapidly transported around the world from their 
place of production to their site of consumption. Although only comprising $0.5 \%$ of total trade volume, airfreight accounts for approximately $35 \%$ of all global trade by value (ATAG, 2012).

While the immediate socio-economic benefits of commercial aviation are difficult to refute, the routine aeromobility of tens of thousands of commercial aircraft and the combustion of millions of barrels of jet fuel a year generate a range of negative externality effects, the likely impacts of which are only now starting to be appreciated. Although some of aviation's deleterious environmental effects, including aircraft noise and atmospheric emissions, were recognised as early as the 1950s and have become synonymous with the aviation-environment debate, issues relating to commercial aviation's impact on human health, its role in the rapid international dissemination of agricultural pests and infectious diseases, and its contribution to anthropogenic climate change, have only more recently become the subject of sustained academic debate.

Although significant steps have been taken to reduce aircraft noise and improve environmental performance in recent years through the development and introduction of progressively more aerodynamic and fuel efficient airframes and engines together with enhanced air traffic management procedures, commercial aviation is now rapidly reaching a point of diminished returns as global increases in the number of flights outstrips the incremental environmental efficiency gains afforded by the introduction of new technology. While some industry commentators and proaviation lobbying groups opine that continued technological innovations in the fields of material sciences, aerodynamics, precision area navigation and propulsion will provide viable and costeffective solutions to aviation's environmental challenges, environmentalists and many airport communities are more sceptical. Indeed, for the sector's most strident critics nothing short of a fundamental step change in aeronautical technology and/or the complete abolition of flying would improve the sector's environmental performance.

In recognition of the increasingly urgent sustainability and public relations challenges the world's commercial aviation sector faces, this chapter critically appraises the role of selected technological innovations and interventions that have been proposed to mitigate some of aviation's principal environmental effects and assesses the extent to which they may individually and/or collectively help to improve aviation's environmental performance. Our focus here is very much on technologies that may reduce the environmental effect of aircraft in flight. The potential roles of new regulatory regimes, global emissions targets, demand management measures, and aviation corporate social responsibility agendas are discussed elsewhere in this volume.

The chapter begins with a brief description of the scope of the contemporary aviation sustainability challenge. This is followed by a section that charts the historical evolution of aeronautical technology from the origins of heavier-than-air powered flight at the beginning of the twentieth century to the present day to explain the sector's contemporary reliance on carbon-based fuels. Section three describes and critically evaluates a range of technological proposals that have been advanced as a way to help improve aviation's environmental performance. The chapter concludes by suggesting that while any future environmental improvements and fuel efficiency gains are welcome, they must deliver tangible environmental benefits over existing technology that not only offset but ideally mitigate future increases in the number of flights. Given the apparent absence of quick technological fixes that will confer the carbon and emissions savings atmospheric and earth systems scientists consider necessary to avoid potentially catastrophic climate change (see Bows and Anderson, this 
volume) a range of new demand management measures, that would undoubtedly be politically unpopular and socio-economically problematic to devise and implement in a globally equitable manner, may ultimately also need to be considered.

\section{From gate to gate: aviation's environmental impact examined}

It is a well-known fact that aircraft noise and atmospheric emissions from aircraft engines respectively degrade the local acoustic environment and air quality around airports and contribute to anthropogenic climate change. In order to provide sufficient thrust to accelerate a passenger aircraft which, in the case of Airbus's A380 'Super Jumbo' ${ }^{1}$, may weigh up to 560 tonnes, from a standing start into the air, climb it to an assigned cruising altitude of 35,000ft or higher, and safely keep it there for the planned duration of the flight, the world's commercial aircraft fleet collectively consumes approximately 5,270,000 barrels of energy-rich and relatively volatile kerosene-based jet fuel a day (Chevron Aviation, 2006; EIA, 2012). The current generation of high-bypass turbofan engines that power contemporary wide-bodied aircraft can each produce around $80,000 \mathrm{lbs}$ (over $36,300 \mathrm{~kg}$ ) of thrust and, at take-off power, draw in over a ton of air through the front fan every two seconds (Snow, 2000). The act of drawing in cold air at the front of the engine, compressing a proportion of it, adding fuel to this compressed air, and igniting that fuel in the central combustion chamber, produces a constant exothermic reaction. The hot exhaust gases that are produced are directed out of the rear of the engine where they mix with the cold air that has bypassed the central core. The act of expelling hot exhaust gases and mixing them with cold air creates additional thrust and ensures an aircraft's wings can generate sufficient lift to overcome the combined effects of gravity and aerodynamic drag.

However, while jet fuel is an undeniably useful energy-rich power source, it produces a number of pollutants, including oxides of carbon, nitrogen and sulphur, methane, water vapour, particulates (soot), and non-methane volatile organic compounds (NMVOCs) when it is burnt. Depending on the altitude and latitude at which they are released, these pollutants can perturb the global climate and cause local air quality around airports to deteriorate. Near the ground, elevated concentrations of nitrous and sulphurous oxides degrade local air quality and have been implicated in a range of human respiratory and cardiovascular complaints. At higher altitudes during the cruise, carbon dioxide, water vapour, and methane contribute to the radiative forcing of the atmosphere and are implicated in anthropogenic climate change.

While the white contrails that are produced by aircraft flying through saturated air at cruising altitude are arguably the most visible and familiar manifestation of aviation's environmental impact, the sustainability challenges the sector faces permeates every stage of the service delivery chain. Processes of airframe and engine manufacturing, maintenance, and disposal are all highly energy intensive. They often involve the use of toxic chemicals and rare earth minerals and create complex man-made composites that can be problematic to reclaim, recycle and/or dispose of safely. The construction of airport passenger terminals, cargo hubs, runways, taxiways, maintenance areas and associated airside infrastructures all require the use of substantial quantities of raw materials (all of which have to be quarried and/or refined, and transported to the construction site). Building works

\footnotetext{
${ }^{1}$ See Airbus.com Dimensions and key data, A380 (2012).
} 
inevitably disturb local habitats. They may displace (as well as intrude upon) local residential communities and can require significant land take, often of greenfield sites. As a consequence, the construction and expansion of airports worldwide has proved controversial almost since the earliest days of powered human flight and many development schemes have been met with vociferous local opposition and public protest.

While anti-airport expansion and anti-noise campaigns are a familiar manifestation of public anxiety about the environmental impact of aviation in many countries around the world, airport construction is only one aspect of aviation that imposes an environmental burden. Once an airport is operational, routine turnaround activities and aircraft maintenance on the airfield demands the use and/or disposal of toxic fuels, lubricants, hydraulic fluids, de-icing and anti-icing compounds, human waste, and catering refuse. Crash simulations and routine emergency exercises by airport rescue and fire fighting services necessitate the burning of kerosene and the use of toxic fire-retardant compounds while strict wildlife management policies - from regulating the height of trees under the final approach paths to runways, to bird displacement activities and the culling of problematic animal and bird species - are practiced to protect the safety of aircraft and their occupants. All these activities, while designed to reduce the inherent risks associated with air travel to an acceptable level, also inevitably affect the local environment and local biodiversity around airports.

Routine operations in the passenger cabin of aircraft also generate a significant environmental footprint. In-flight meals demand the procurement, preparation, storage and carriage of fresh, culturally-appropriate, and appealing foodstuffs, and the provision of disposable serving equipment and suitable temperature storage and reheating facilities prior to consumption. Used meal trays contain co-mingled waste food, plastic, film, foil, paper, can, and ceramic waste, much of which was, until recently, collected in refuse sacks and sent to landfill. Passenger utility and entertainment services, from aircraft lavatories (it has been estimated that one in-flight flush uses two litres of aviation fuel), to potable water supplies, in-flight entertainment systems, and the provision of miscellaneous items such as in-flight magazines and blankets require airlines to burn additional fuel to generate both the extra electrical energy that is needed to power the on board systems and the extra thrust that is required to keep the (now heavier) aircraft in the air. If the aircraft has arrived from an overseas country in which certain infectious diseases are endemic, the cabin may also have to be disinsected using powerful pesticides and insecticides to prevent the importation of disease and protect human health.

On the ground, aircraft turnarounds and passenger terminals require significant quantities of electrical energy, gas, and potable and non-potable water. Waste disposal systems, capable of processing everything from human sewage and retail waste to obsolete, but still radioactive, $x$-ray and baggage screening equipment, must be provided. Telecommunications, security, air conditioning, fire detection, and heating systems are all now prerequisites of modern airport operations. Restaurants and retail outlets need regular supplies of (often chilled) perishable products, while staff, passengers, contractors, and visitors may need to access the site 24-hours a day. As T Budd et al (2011) have shown, for reasons of cost, comfort and convenience, most surface access journeys to and from airports worldwide are conducted by private cars and taxis. The dominance of private vehicles in the surface mode split results in a significant deterioration in local air quality as well as delays and congestion on airport access roads. 
Despite aviation's wide-ranging environmental effects, it is only within the last few decades that concerted attempts have been made to improve the sector's environmental performance. Many of these early efforts were driven by the need to improve fuel efficiency and lower costs during the oil price rises and oil crises of the 1970s whereas more recent ones have emerged in response to growing consumer and regulatory pressure to reduce aviation's environmental impact and act in a more socially and environmentally responsible manner. In the next section we review the development of aeronautical technology from the first heavier-than-air powered human flights in 1903 to the present.

\section{Aviation technology - the first 100 years}

The world's first heavier-than-air powered human flight occurred on the morning of December $17^{\text {th }}$ 1903 on the windswept sand dunes of Kill Devil Hills, near Kitty Hawk, North Carolina. Although only airborne for 12 seconds and barely covering a distance of $120 \mathrm{ft}$, Orville Wright became the first aviator in the history of human aeronautical endeavour to take off, successfully pilot an aircraft, and land at a point equal in elevation to that at which he departed. The Wright brothers canvas and wood biplane marked an important moment in aircraft design. Unlike the experimental gliders and flying machines that had preceded it, the Wrights had fitted a gasoline-powered 12 horsepower internal combustion engine to their machine. This engine powered a propeller that was angled to pull the aircraft through the air and generate sufficient airflow over the wings to overcome the increased drag and the weight of the aircraft. Although the engine was noisy, underpowered, unreliable, and generated noxious emissions, gasoline proved to be an ideal fuel for early aircraft as it was energy intensive, relatively cheap, reasonably safe to store and handle, readily available, and didn't congeal in cold temperatures. As such, gasoline-fuelled engines became the powerplant of choice for early aviators.

The years leading up to the outbreak of the First World War in 1914 were marked by the progressive application of scientific knowledge to aircraft design. The outbreak of the First World War stimulated rapid advances in aircraft design and manufacturing techniques. The conflict identified a number of unique roles that aircraft could perform and a new range aircraft were designed for purposes of aerial reconnaissance, surveying, and bombing. The war helped to identify the most efficient and reliable designs and, as time went on, designers quickly standardised on single wing monoplanes that were powered by one or more petrol engines that drove a front mounted propeller. The development of more powerful and reliable piston engines in the 1930s enabled designers to build larger and heavier aircraft and metal became the material of choice for aircraft construction.

The start of the Second World War in 1939 again stimulated rapid advances in aircraft technology and resulted in striking new innovations in aerodynamics, propulsion, navigation, and communication systems. The advent of the gas turbine (or jet) engine by Sir Frank Whittle and colleagues revolutionised first military and, a few years later, commercial aviation. Fuelled by special aviation-grade kerosene derived from crude oil, jet engines conferred significant increases in power and performance for only a modest increase in weight and they enabled aircraft to fly further, faster, longer, and higher than ever before. Military jet fighters, which could outperform and outmanoeuvre the earlier propeller-driven aircraft, were quickly developed and, soon after the War ended, the new jet age technology was being applied to a new generation of post-war passenger 
aircraft. British aircraft manufacturer de Havilland, responding to the UK Government's call for a new generation of long-haul jet-powered passenger transport, designed the world's first jet powered commercial aircraft, the Comet. The Comet first flew in 1949 and, following a rigorous programme of ground and flight testing, entered revenue passenger service with British Overseas Airways Corporation (BOAC) on the London to Johannesburg route in May 1952. Despite its early promise, the Comet's commercial success was irrevocably damaged by a series of fatal accidents that were the result of metal fatigue that had been caused by repeated cycles of cabin pressurisation. Nevertheless, the jet engine had proved it was suitable to power commercial aircraft and other aircraft were designed to take advantage of the increased speed, power, and range jet engines afforded.

In the United States, major American aircraft manufacturers including Boeing and Douglas began designing jet aircraft of their own. Boeing's B707, which could seat over 100 passengers and which was powered by four jet engines, entered service with Pan American Airlines on their transatlantic routes in 1959. Although much faster and more comfortable than the aircraft they replaced, the first generation of jet aircraft were very noisy and had a prodigious thirst for fuel. As a result, people living near major commercial airports quickly began complaining about the peculiar shrill squeal of jet engines that would rattle their windows and render normal conversation impossible when aircraft passed overhead. In addition to being noisy, the early jets were also very inefficient by today's standards and very polluting. Thick black trails of soot could often be seen in the sky behind departing aircraft and this led to growing public concern about the environmental impact of flying.

The late 1960s and 1970s saw the introduction of the B747-100 'Jumbo' Jet and other wide-bodied passenger aircraft. These machines could seat between 250 and 500 passengers and regularly undertake flights of eight-hours or more duration. However, the 1973 oil crisis pushed the price of crude oil and aviation fuel to record levels. As fuel constituted one of an airline's biggest costs, aircraft manufacturers came under increasing pressure to design more fuel efficient aircraft. Engine manufacturers, in particular, now had a new commercial imperative to develop more fuel efficient products that were not only safe but also cheaper to operate. This led to Innovations in turbine design, which included the use of stronger and lighter composite materials, the development of new lighter metal alloys, and the introduction of higher-bypass turbofans that progressively reduced the amount of fuel that was required to deliver an equivalent unit of thrust.

Rather than all the air passing through the central core of the engine, scientists discovered that if they mixed cold air with the hot air in the exhaust plume they could further increase the power (thrust) of the engine without increasing fuel burn. The resulting new 'high bypass' engines were not only more powerful and fuel efficient, they were also less noisy than the earlier designs. While highbypass turbofan engines conferred significant improvement in environmental performance, even the most modern fuel efficient engines still burn a finite carbon intensive fossil fuel and produce a range of harmful pollution species as a result of combustion. Similarly, despite notable reductions in engine noise, the acoustic energy that is created by aircraft remains a highly contested moral and geopolitical issue and airlines, airports, aircraft manufactures, and national Governments are under increasing pressure to reduce aviation's environmental impact still further and a range of potential solutions to these challenges have been proposed. In the next section of this chapter we critically review the extent to which suggested innovations in aircraft design, materials, alternative fuels, and more sophisticated navigation systems can help to reduce aviation's environmental impact. 


\section{The prospects for new technology}

In recognition of the need to improve aviation's environmental performance, a number of purportedly 'transformative' new technologies have been proposed. Some of these concern the design, materials, and construction of the airframe, others refer to potential changes to propulsion systems and alternative power sources for aircraft while others concern technologies that seek to improve ATC efficiency and lessen the environmental impact of routine airport operations. It is to these technologies that the chapter now turns.

\section{Materials}

Historically, innovations in aircraft design were driven by demands for increased speed, reliability, and performance. In the space of a few years, canvas and wood biplanes were replaced by metal monoplanes and primitive engines surpassed by more powerful piston designs. The use of highgrade steel and the development of stressed-skin aluminium alloys from the late 1930s onwards allowed aircraft designers to build ever-stronger and more complex designs (Whitford, 2000). Continued innovations in aircraft materials resulted in the introduction of progressively lighter yet stronger aluminium and titanium alloys that were resistant to corrosion, cracking, and fatigue. As a result, these materials were the metals of choice for passenger aircraft during the 1960s and 1970s. By the 1980s, however, it had been discovered that other materials, including carbon-fibre composites, could be manufactured to exhibit the properties required for aircraft structures. These carbon fibre composites are made from strong carbon fibres that are set in a chemically and mechanically protective matrix of epoxy resin (Whitford, 2000). Crucially, these carbon-fibre composites are both strong and up to $20 \%$ lighter than aluminium alloys. Carbon-fibres were first used in a limited capacity on Airbus's A300 aircraft in 1980 and are now used by most aircraft manufacturers in a variety of structures including the fin and fuselage. It is estimated that the Airbus A340 would have been $11,595 \mathrm{~kg}$ heavier if carbon fibre composites had not been used (Ibid, 2000). Clearly these weight reductions are significant and Boeing's twin engine B787 Dreamliner is the first commercial passenger aircraft in history to have a fuselage built from these lighter carbon fibre composites and over $20 \%$ of the A380 is made from composite materials, including carbon-fibre reinforced plastic.

The development of new polymers, composites, and memory metals that are stronger but lighter than conventional aluminium alloys will lead to continued reductions in weight and fuel burn. Already, another composite material, glass fibre reinforced aluminium is reported to be $25 \%$ stronger than conventional airframe grade aluminium but around $20 \%$ lighter. Nevertheless, despite the weight reductions these new materials confer, the environmental impact of the processes involved in their manufacture and disposal need to be taken into consideration when the environmental benefit of these new materials is assessed. What is certain, however, is that over time research and development into new aircraft materials will enable the construction of new, perhaps radically different, aircraft.

\section{Aircraft designs and airframe configurations}

In addition to reducing the weight of aircraft by using new materials, improving the aerodynamic efficiency of the airframe by lessening drag is another key tenet of future aircraft design, and various technologies and innovations have been proposed and tested in recent years, with varying degrees 
of success. The basic configuration of most modern subsonic jet powered passenger aircraft, with their sleek fuselages, under-wing mounted high-bypass turbofan engines, and swept back metal wings, has not changed dramatically over the last 60 years. This has led some aircraft designers to speculate on whether this conventional design remains the most effective and environmentally efficient. Certainly, a number of alternative configurations, including blended and strut-braced wings, which focus on altering the shape of the wings to improve their lifting properties while reducing drag, have been proposed.

Unlike standard aircraft where the wings are attached to the fuselage, with blended wing designs the wing structures are incorporated into the main structure of the aircraft. This gives the aircraft a more bulbous shape that, when viewed from above, resembles a delta wing. Interestingly, the idea of a blended wing was first tested in the 1920s but the lack of suitably strong materials prevented its development. Within the last few years, a number of scientists have proposed revisiting the design as they believe it would be more aerodynamically efficient and quieter than existing aircraft. Critics, however, have questioned whether passengers would be prepared to travel long distances in an aircraft that had few (if any) windows and may be claustrophobic. Other radical new aircraft designs include 'flying wings'. These designs share many of the characteristics of blended-wing aircraft but typically lack a defined fuselage or vertical stabiliser. Advocates of flying wings believe the design will confer much more favourable lift-to-drag ratios compared with conventional aircraft. However, while such designs may provide improved aerodynamic and structural efficiency, the absence of traditional stabilisation surfaces on the leading and trailing edges of the wing and empennage means that they may be more unstable and therefore difficult to control. As a result, blended-wing and flying wing aircraft may never enter commercial service.

Other designs which have been advocated include strut-braced wings. This configuration, in which supporting struts are added between the wings and the fuselage, was also tested and largely abandoned in the 1920s but it is now being revisited. Adding supporting struts between the wings and the fuselage enables the wings to be lighter and longer. This reduces weight and drag and helps to increase the lifting area of the wing. Researchers in the United States have calculated that adding a supporting strut from the belly of the aircraft to the wings could enable airframe designers to reduce the weight of the wing by two thirds without compromising its strength or its ability to generate lift (Daviss, 2007). This, they believe, could improve fuel efficiency by $25 \%$ (Daviss 2007).

An altogether easier, yet still effective, strategy to improve the aerodynamic properties of aircraft currently in service involves the addition of raked wingtips or wingtip fences. These devices are installed at the very end of the wings to smooth the interface between the turbulent airflows above and below the wings to reduce wingtip vortices and lessen drag. Most new aircraft are equipped with wingtips as standard but many older airframes are being retrofitted with wingtips to lessen drag and improve fuel efficiency. The ability to retrofit existing aircraft is very beneficial for airlines given the long life cycle of commercial aircraft and the capital expense of purchasing new ones.

A further wing-based innovation that has the potential to improve environmental performance is the use of laminar flow control technology. In the context of aircraft design, laminar flow describes the layer of air that passes over the wings and fuselage of the aircraft providing lift and keeping it airborne. The smoother the layer of air, the less drag and the less fuel you burn. Laminar flow control works by detecting and sucking turbulent air into the aircraft through tiny holes in the 
airframe. This has the effect of retaining a smooth layer of air close to the surface. It is estimated that the use of laminar flow control can reduce drag on the wings by up to $20 \%$ and result in a $10 \%$ fuel saving. However, research into laminar flow control largely ceased in the 1990s when fuel prices dropped and the cost of the equipment would have outweighed any advantages in terms of reduced fuel burn. Other ideas have included combining laminar flow control with a specially modified fuselage to cut engine thrust by up to $60 \%$ in the cruise and result in fuel savings of $20 \%$ or, more radically, employing military aviation-esque shape shifting designs that actually alter the shape of the aircraft according to flight stage to maximise efficiency (Daviss, 2007).

\section{Engines}

As well as changing the materials that are used to build aircraft and the design of the airframes themselves, it may also be possible to significantly improve aviation's environmental performance by redesigning aircraft engines. Allow very small incremental efficiency gains may be achievable with existing technology, others have proposed that a new generation of open rotors or propfan engines may represent the best opportunity to improve environmental performance. The proposed open rotor or propfans use a modified jet engine that drives specially shaped propellers that create less drag. Though slower and noisier than a conventional jet engine, open rotor engines use less fuel and could give fuel savings of up to $30 \%$. However, safety concerns about the effects of a blade failure on an open rotor engine may take some time to resolve (on current engines, blade failures are contained by the engine cowling that surrounds the fan. As the name implies, open rotors are not surrounded by this protective barrier and so could, theoretically, strike the aircraft's fuselage if they broke free following a bird strike or a structural failure).

\section{Power sources}

In addition to proposing alternative designs for engines, attention has also been focused on the fuels that are used to power them and concerted efforts are being made to develop fuels that are not only more sustainable to produce but which also do not emit as many environmentally damaging pollutants when burnt. One of the main challenges associated with developing alternative fuels for aviation is that gasoline and (later) kerosene-based fuels exhibit the qualities required of a fuel. They have also been used since the early days of aviation which means that not only is there a significant body of knowledge about the fuels but also that a substantial supply chain and system of fixed infrastructure has evolved to support their use. The embedded nature and historical inertia of jet fuel in modern aviation represents a major barrier to the search for alternatives as any new fuel must be a direct substitute that can be 'dropped in' to the existing fuel supply chain without recourse to expensive and time consuming modifications to the supply chain. Nevertheless, aviation's reliance on jet fuel leaves airlines vulnerable to sudden changes in fuel price and the introduction of increasingly stringent environmental targets, emissions trading schemes, and growing consumer concern about the environmental effects of flying, are now driving developments into alternatives.

One of the most promising developments relates liquid biofuels. Unlike conventional jet fuel which is refined from crude oil, biofuels are created by chemically processing biomass (plant starches and sugars) to create a liquid energy source. While biofuels (particularly ethanol and plant oils) had been used to power road transport vehicles since the 1970s, it is only within the last couple of years that new blends that are suitable for use in aircraft have been developed. Aviation biofuels that are 
currently undergoing flight testing with major airlines worldwide have been produced from a range of feedstocks and biomass including jatropha, coconuts, algae, domestic refuse, woodchips, and carmellia (an inedible green shrub).

Over 50 major airlines, including KLM, Thomsonfly, Virgin Atlantic, United, and Air New Zealand, have performed test flights using different types and blends of biofuel on a range of different aircraft types in both revenue and non-revenue services. Significantly, the biofuels were considered to be as good as conventional jet fuel as the test flights reported no loss of engine performance. However, while biofuels are being promoted as a 'green' alternative to conventional jet fuel, a number of barriers to their widespread use remain. Currently, we are unable to produce enough biomass to replace conventional jet fuel. This has led to concerns that land will be used for biofuel crops rather than for food production which would have the effect of pushing up world food prices and potentially driving more people into food poverty. Other concerns relate to the high research and development costs of biofuel (and thus their relative expense versus jet fuel), uncertainties about the accounting procedures, the true life-cycle emissions savings of the fuels, and issues relating to fuel consistency.

Although biofuels are being strongly advocated by some sections of the aviation community as a potential solution to aviation's environmental impact in the short to medium-term, other possible power sources, including solar energy and hydrogen fuel cells, are also being explored. In the summer of 2010, a single-seat experimental solar-powered aircraft, the Solar Impulse, successfully completed a 24-hour test flight. The aircraft was fitted with propeller driven electric engines that were powered by solar energy generated by the 12,000 photovoltaic cells on the upper surface of the wings. Other experimental flights using solar power and/or batteries have indicated that while they could power small (single or dual seat) aircraft they do not supply enough electrical energy to power larger aircraft and their inferior energy-to-unit mass ratio remains problematic. Indeed it has been estimated that batteries only produce $2 \%$ of the energy that is obtained from the same mass of petrol.

While the potential for using solar power and electricity to power aircraft is very limited at present, another potential power source, hydrogen fuel cells, have also been proposed. It is suggested that, following suitable refinement, hydrogen fuel cells could be used to drive electric motors that would power aircraft. However, the application of hydrogen fuel cells to aircraft is immature and while the use of such cells would eliminate pollution at point of use, the processes of producing the hydrogen and manufacturing the fuel cells both require energy and generate atmospheric pollution.

\section{Enhanced air traffic control procedures}

In addition to proposing and developing new aeronautical hardware, such as airframes, engines, and alternative fuels, to reduce aviation's environmental impact, new technology, in the form of more sophisticated computer software and processing capabilities, is also enabling the more effective use of airspace. Increasingly advanced air traffic control procedures that use precision satellite navigation and multilateration radar enable aircraft to fly more efficient trajectories and operate more environmentally friendly arrival and departure routes. Many airports have refined their existing air traffic control procedures to facilitate more environmentally efficient continuous climb departures (CCDs) and continuous descent approaches (CDAs). CCDs and CDAs enable aircraft to continuously climb up to, and descend from, their cruising altitudes without being held at 
intermediate altitudes. The elimination of old 'step up' and 'step down' climbs and descents enables pilots to fly their aircraft in a more aerodynamic configuration for longer. This reduces drag and avoids continuous adjustments being made to engine thrust settings, both of which collectively lower emissions.

Once established in the cruise, the increased use of user defined trajectories (in which airlines and flight crew request the most fuel efficient altitudes, headings, and routings based on aircraft type, aircraft weight, and en route weather conditions), better aircraft sequencing at airports, and experiments to create 'perfect flights' all lead to a reduction in emissions from individual aircraft. Individual air navigation service providers (ANSPs) are at the forefront of developments to improve environmental efficiency and reduce the volume of emissions each flight generates. The UK's ANSP, NATS, has committed to reducing air traffic related carbon dioxide emissions by an average of $10 \%$ per flight by 2020, from a 2006 baseline (NATS, 2012a). They estimate that approximately $2 \%$ of this reduction will come from operational improvements in their air traffic control centres, a further $2 \%$ from the use of CCDs and CDAs at airports, and 6\% from reconfiguring airspace structure and introducing new technology (ibid, 2012a). A further NATS initiative involves calculating the three dimensional inefficiency of the flights they control. Using a specially designed environmental metric, called the 3Di score, NATS can compare actual flight trajectories with an optimal or airline preferred trajectory that minimises carbon dioxide emissions (NATS, 2012b).

In addition to individual ANSPs improving the environmental performance of flights operating within their airspace, there is significant potential to improve airspace coordination internationally. European airspace, in particular, is a patchwork of fragmented sectors and control zones that were originally drawn up along sovereign territorial lines. This historical legacy means that European airspace is not optimised for environmental efficiency and aircraft often have to fly circuitous routes to avoid congested areas, to prevent overflying certain nations, and to avoid the most expensive areas of airspace. Attempts to harmonise the existing European airspace network through the Single European Skies Initiative is being delayed by a lack of international consensus.

\section{Airport operations}

In addition to improving the environmental performance of aircraft in the air, technology is also being used on the ground to make airport operations more environmentally efficient. Increasing the use of energy from renewable sources is one way in which airport operators are improving their environmental performance. Lighting, heating, cooling, servicing, and ventilating large passenger terminals can be extremely energy intensive and expensive and so airports are developing new systems that can produce reliable and affordable sustainable energy and lower energy costs. Many airports have installed biomass boilers, worked to increase the amount of natural light and ventilation, and, in some cases, installed wind turbines to generate electrical energy and boreholes to exploit sources of geothermal energy. The use of solar panels to convert sunlight into electrical energy has already been implemented at a number of airports in North America and Australia and there is scope for using similar technology at Middle Eastern and (some) European airports. Airport tenant companies, including airlines and ground handling companies, are installing solar panels on their head offices and administration buildings to reduce energy consumption and some are working towards making their building estate carbon neutral. Airports are also trialling the use of electrically powered vehicles, are encouraging shops and catering suppliers to source local seasonable produce, 
are harvesting rainwater to flush lavatories, and are encouraging their staff and passengers to arrive at the airport by more environmentally efficient forms of transport.

\section{Surface access}

Prompted by a growing awareness of the environmental impacts of the airport users entire 'door-todoor' journey, technology is also being used to reduce the environmental impacts of travel to and from airports. The environmental impacts associated with surface access travel typically relate to issues of noise and visual intrusion, local air pollution, carbon emissions, loss of habitat and biodiversity, as well as other environmental degradation (Graham, 2008; Caves and Gosling, 1999; Johnson, 1997). While aircraft emissions have traditionally been the focus of debates about the environmental impacts of aviation, the role of surface access travel should not be overlooked. For example, it is estimated that $80 \%$ of local air pollution at Heathrow Airport is derived from surface access traffic and airside vehicles (Humphreys et al, 2005).

Technological innovations have typically been targeted at reducing the share of private vehicle trips in favour of promoting public transport use. Advanced transportation system, such as personal rapid transit (PRT) systems, have been successfully implemented at a number of airports worldwide. These systems typically consist of small, fully automated carriages or 'pods' that run on a guide-way, such as an elevated track, to and from the airport terminal utilising an 'on-demand' style service. These systems may be attractive options for airport operators, as their costs and service attributes compare favourably with alternatives such as shuttle buses or automated people movers, and the level of emissions associated with them is negligible (Gavin and Duncan, 2005; Muller, 2005). Examples of existing PRT systems include the 'ULTra' system in operation at Heathrow Airport, and the '2getthere' service at Amsterdam Schiphol. While to date such systems have only typically been used to connect remote locations on the airport site (such as car parks) to the terminal building, there is clear scope for their extension to include trips from a wider area, for example from downtown regions.

Other initiatives are designed to encourage and facilitate public transport use. Access (or lack of access) to travel information is identified as a key factor in decisions to travel by public transport, and as such a number of airports offer mobile applications (or 'apps') that convey real time travel information to airport users about transport service schedules and attributes, information about delays and route planning facilities. The increased demand for traveller information services has been driven to a significant degree by the rapid technological advances and the use of smartphone and tablet devices in recent years (Marshall Elizer Jr et al, 2012).

\section{Other technologies}

Other suggestions for lessening aviation's environmental impact include revisiting older aeronautical technologies, such as the airship, and accepting slower forms of aero mobile travel. In an increasingly globalised world that relies on fast, efficient and safe air travel, the scope for the widespread use of such technologies is perhaps limited. Alternatively, much has been made of the possibility for conducting virtual meetings via advanced teleconferencing and internet video/phone technologies, which, at least in theory, negate the need to travel at all. To date, research into their effects on air travel is inconclusive with some studies suggesting that the availability of virtual means 
of meeting reduce demand for air travel, whereas others have shown that, conversely, they promote it.

\section{Conclusion}

Technological innovation has played a key role throughout aviation's historical development. Since the first powered flight by the Wright brothers in 1903, through the two world wars, the jet age and eventually on to modern day aviation, technological advances in aircraft design and manufacturing, engine design and navigation systems have been rapid. While the evolution of aeronautical technology has created all sorts of new opportunities for increasing the speed and volume of global travel and trade, it has also imposed a number of significant social and environmental costs that the sector has not always been quick to address. In recent years, however, growing concern and awareness of the environmental impacts of the industry has prompted a shift towards developing technologies that reduce aircraft noise and improve the sector's environmental performance.

This has led to significant progress in the design and construction of airframes, propulsion systems and alternative power sources. There remain, however, numerous barriers to the widespread adoption of many of these technologies in a commercial aviation setting in the short to medium term. In particular, the long-life cycle and high capital expense associated with purchasing new aircraft means that new initiatives may take many years to filter through, while existing supply chains and systems of fixed infrastructure remain a significant barrier to widespread uptake of more sustainable fuels, not to mention concerns relating to the designation of land for growing crops for biofuels when millions of people around the world remain in food poverty.

Arguably the most successful innovations are those that can be retrofitted to existing aircraft and/or 'dropped-in' to established supply chains and fixed infrastructure as they can typically be implemented much more quickly and cost effectively. The recent trend for retrofitting raked wingtips or wingtip fences on current aircraft is a good example of such practices. While such modifications are perhaps unlikely to single-handedly 'solve' aviation's environmental problem on their own, smaller incremental changes such as this can yield significant overall benefits when combined with a number of improvements in other areas.

Similarly, progress in technologies for improving ATC efficiency and lessening the environmental impact of routine airport operations are likely to be yield the greatest benefit when they are implemented as part of a wider programme of technological innovation. The increased use of precise satellite navigation and multilateration radar for ATC systems and the growing trend for airports to use renewable energy sources for powering terminal operations are testament to the progress being made. It is important that decision makers continue to address potential barriers and pitfalls for future improvements, for example the on-going need to tackle political barriers associated with the implementation of the Single European Skies initiative.

While much of the focus on aviation and the environment has understandably focused on aircraft and airport operations, it is also important that decision makers do not lose sight of the environmental impacts of associated activities, such as surface access. Here, it is likely that technology will have a role to play by giving airport users the ability to make more informed sustainable travel decisions, rather than actually cutting emissions at source. 
An examination of environmental technology and aviation highlights a number of important wider issues. In debates about the role of environmental technology and aviation, questions relating to environmental and technological interdependencies persist. Perhaps most notably, while aircraft can be made to be significantly quieter or less polluting, achieving both at the same time is a much harder prospect. This raises difficult questions about the prospect of prioritising reductions in aircraft emissions over reducing noise impacts, or vice versa. In essence, such debates boil down to striking a balance between the immediate annoyance and social problems resulting from aircraft noise, with longer term issues relating to air pollution and climate change which are harder to quantify and may not be felt for years or decades to come.

Finally, we believe it is important that advances in technological innovations are not seen as a 'get out of jail free' card and used to justify unsustainable future expansion; emissions savings from environmental technologies are likely to be lost if there are simply many more aircraft in our skies. It is therefore vital that technology is developed and applied in a sustainable fashion, and that such innovations complement, rather than contradict, wider policy or fiscal measures aimed at ensuring a more environmentally sustainable aviation future.

\section{References}

Airbus (2012). Airbus - Dimensions and Key Data, A380 Retrieved from www.airbus.com on $17 / 10 / 2012$.

Air Transport Action Group (2012). Aviation. Benefits Beyond Borders. Geneva, ATAG.

Caves, R. and Gosling, G. (1999). Strategic Airport Planning. Pergamon, Oxford.

Chevron Global Aviation (2006). Aviation Fuels Technical Review. Houston, TX, Chevron.

Daviss B (2007). Green sky thinking. New Scientist, 24 February 2007, pp32-38.

Gavin,W. and Duncan, R. (2005) Personal Rapid Transit at Airports: Physical, Operational, and Financial Considerations, Conference paper presented at the $84^{\text {th }}$ Annual Meeting of the Transportation Research Board, Washington, DC.

Graham, A (2008). Managing Airports: An international perspective $3^{\text {rd }}$ Edition, ButterworthHeinemann, Oxford.

Humphreys, I., Ison, S., Francis, G., and Aldridge,K (2005). UK airport surface access targets, Journal of Air Transport Management, Vol. 11,No. 2, pp. 117-124.

Johnson, $T$ (1997) Environmental Issues, Conference presentation at the $2^{\text {nd }}$ Annual European Convention on the Development of Surface Access Links to Airports, Chartered Institute of Transport, London.

Marshall Elizer, Jr., R., Hoskins Squier, D., Brydia, R, E., and Beaty, C, P. (2012) Guidebook for Implementing Intelligent Transportation Systems Elements to Improve Airport Traveler Access Information, Airport Cooperative Research Programme (ACRP) Report 70,Transportation Research Board of the National Academies, Washington, DC. 
Muller, P. J. (2005) Personal Rapid Transit, an Airport Panacea? Conference paper presented at the $84^{\text {th }}$ Annual Meeting of the Transportation Research Board, Washington, DC.

NATS (2012a) Corporate responsibility report 2012 Available online at http//www.nats.co.uk/wpcontentuploads/2012/07/corportateresponsibilityreport2012.pdf Accessed 20/10/2012.

NATS (2012b) 3di infocard Available online at http://www.nats.co.uk/wpcontent/uploads/2012/07/3di_infocard.pdf _ Accessed 20/10/2012.

Snow, J (2000). Airliner propulsion in Jarrett P (Ed.) Modern Air Transport Worldwide Air Transport from 1945 to the Present London, Putnam pp53-66.

US Energy Information Administration (2012) Jet Fuel use statistics. Available online at www.eia.gov, accessed on 09/10/2012.

Whitford, R (2000). Structures and materials in Jarrett P (Ed.) Modern Air Transport Worldwide Air Transport from 1945 to the Present London, Putnam, pp. 67-80. 